CHROM. 3468

\title{
GAS CHROMATOGRAPHIC SEPARATION OF LOW MOLECULAR WEIGHT FLUOROCARBONS
}

ROBERT N. BRIGHT AND RICHARD A. MATULA *

Fluid Dynamics Laboratory. Department of Mechanical Engineering, College of Engineering. The University of Michigan, Ann Arbor, Mich. (U.S.A.)

(Received February I9th, 1968)

SUMMARY

Application of gas-solid chromatography techniques to the separation of low molecular weight fluorocarbons incorporates a number of advantages over previous analysis techniques. These advantages include isothermal operation up to $200^{\circ}$, elimination of substrate bleed, stability of the base line, minimum retention times and convenience. The relative retention volumes with respect to perfluoroethane of a number of low molecular weight fluorocarbons as a function of column support material and operating conditions are reported. The separation of a number of important species which are formed during the thermal oxidation of low molecular weight fluorocarbons are also discussed.

INTRODUCTION

The qualitative and quantitative analysis of low molecular weight fluorocarbon mixtures has many applications including analysis of various fluorocarbon refrigerants, quality control of certain aerosol products and kinetic studies related to the thermal decomposition of fluorocarbons. TATLOW and co-workers ${ }^{1-5}$ have employed gas chromatography techniques for the analysis and preparative separation of a number of perfluorinated and almost perfluorinated cyclohexanes, cyclohexenes and benzenes. REED has studied the chromatography of perfluoroalkanes, $C_{5} F_{12}$, $\mathrm{C}_{6} \mathrm{~F}_{14}$ and $\mathrm{C}_{7} \mathrm{~F}_{16}$ on a range of stationary phases. SERPINE1 ${ }^{7}$ has considered the separation of a number of fluoro- and fluorochlorocarbons. Unfortunately the perfluorinated compounds were eluted rapidly and they were followed by compounds containing at least one other atom which were retained and resolved. CAMPBELI AND GUDzINOwrCZ $Z^{8}$ have reported the separation of various fluorocarbons and sulfur fluoride compounds. GREEN AND WACHI concluded that Kel-F oils were not completely satisfactory for the separation of fluorocarbons. The results of GREEN AND WACHI indicated that a number of low boiling point fluorocarbons could be separated by temperature programming a silica gel column or by maintaining a Chromosorb $W$ column employing $\mathrm{CH}_{2}=\mathrm{CHCO}_{2} \mathrm{CH}_{2}-\left(\mathrm{CF}_{2} \mathrm{CF}_{2}\right)_{3} \mathrm{H}$ (courtesy of E.I. duPont de Nemours and Co., Wilmington, Delaware) as the liquid substrate at $0^{\circ}$. Recently

* Present adress: Department of Mechanical Engineering, Drexel Institute of Technology, Philadelphia, Pa. (U.S.A.). 
DRennan AND Matula ${ }^{10}$ have reported that carbon dioxide and carbonyl fluoride mixtures can be separated on a composite Porapak (Waters Associate, Inc.) column. The purpose of the present paper is to report the relative retention times of a number of low molecular weight fluorocarbons on Porapals cólumis, and to extend the usê iof Porapals columns for the analysis of the products of combustion of low molecular weight fluorocarbons.

TEXPERIMENTAL

\section{Apparatus and reagents}

An Aerograph model No. 202-B gas chromatograpl employing a thernal conductivity detector was used for this study. Mixtures were introduced into the gas chronatograph through a gas sampling valve used in conjunction with a $2 \mathrm{ml}$ sample volume. The chromatograph was equipped with a linear temperature proginaminer which was capable of maintaining isothermal column operation in the temperature range 30 to $400^{\circ}$.

The fluorocarbons utilized in this study were obtained from a number of sources. The perfluoromethane $\left(\mathrm{CF}_{4}\right)$, perfuoroethane $\left(\mathrm{C}_{2} \mathrm{~F}_{0}\right)$ and a mixture of cis and trans$\mathrm{C}_{4} \mathrm{~F}_{8}-2$ were purchased from the Matheson Company, East Rutherford, New Jersey. The 2-trifluoromethylpropene $\left(C_{4} F_{10}\right)$, perfluorobutane $\left(C_{4} F_{10}\right)$, perfluorobutadiene-I,3 $\left(\mathrm{C}_{4} \mathrm{~F}_{0}\right)_{1}$, perfluorobutyne-2, $\left(\mathrm{C}_{4} \mathrm{~F}_{0}\right)$, perfluorocyclobutene, $\left(c-\mathrm{C}_{4} \mathrm{~F}_{0}\right)$, perfluorocyclobutane (c-C $\left.F_{8}\right)$, perfluoropropane $\left(C_{3} F_{8}\right)$, and perfluoropropene $\left(C_{3} F_{6}\right)$ were purchased from Penninsular Chemresearch, Inc., Gáinesville, Florida. The perfluoroethylene $\left(\mathrm{C}_{2} \mathrm{~F}_{4}\right)$ and carbonyl fluoride $\left(\mathrm{CF}_{2} \mathrm{O}\right)$ were purchased from Columbia Organic Chemicals, Inc., Columbia, South Carolina. The iso- $\mathrm{C}_{4} \mathrm{~F}_{8}$ used in this study was produced by pyrolyzing perfluoropropene at $700^{\circ}$ for $15 \mathrm{~min}$ in a Vycor reactor.

\section{Procedure.:}

A number of variable length GSC columns were constructed by packing $I / 4$ in. O.D. copper tubing with 50/80 mesh Poropak (Wâters Associate, Inc.). The separation capabilities of Types N, P, Q, R, S and T Poropak were studied. Before final instillation in the chromatograph, each of the columns was heated to $200^{\circ}$ and purged with helium $(60 \mathrm{ml} / \mathrm{min})$ for two hours. Prior to the analysis of the fluorocarbon combustion products; the column was conditioned by passing three $25^{\circ}$ torr samples of $\mathrm{CF} / 2 \mathrm{O}$ through it. The retention volumes of all compounds wereidetermined from the analysis of both pure compounds and fluorocarbon mixtures that had been prepared in the laboratory. The separations were obtained by operating the columns isothermally in the temperature range 75 to $175^{\circ}$ while maintaining a constant helium carrier gas flow rate of $60 \mathrm{ml} / \mathrm{min}$.

RESUITS AND DISCUSSION

\section{Fluorocarbon analysis}

The relative retention volumes of the various fluorocarbon compounds as a function of column material; length and temperature are listed in Tables. I-IV . All of these results are based on a helium carrier gas flow rate of $60 \mathrm{ml} / \mathrm{min}$. If the relative retention volume of a compound is not listed in the Tables the retention time was 
TABLE I

RELATIVE RETENTION VOLUMES OF SEVERAI FLUOROCARBONS ON PORAPAIS TYPE T $\mathrm{C}_{2} \mathrm{~F}_{0}=\mathrm{r} .00$. Helium carrier gas flow rate: $60 \mathrm{ml} / \mathrm{min}$; column material : $50 / 80 \mathrm{mesh}$.

\begin{tabular}{|c|c|c|c|c|c|c|c|c|c|c|}
\hline \multirow[t]{2}{*}{ Compound } & \multicolumn{2}{|c|}{$6 \mathrm{ft}$. at $100^{\circ}$} & \multicolumn{2}{|c|}{$6 \mathrm{ft}$. at $550^{\circ}$} & \multicolumn{2}{|c|}{$6 \mathrm{ft}$. at I $75^{\circ}$} & \multicolumn{2}{|c|}{ Io ft. at $150^{\circ}$} & \multicolumn{2}{|c|}{ Io ft. at $I 75^{\circ}$} \\
\hline & $t_{m}^{\mathrm{n}}$ & $R R V^{b}$ & $t_{m}$ & $R R V$ & $t_{m}$ & $R R V$ & $t_{m}$ & $R R V$ & $t_{m}$ & $R R V$ \\
\hline 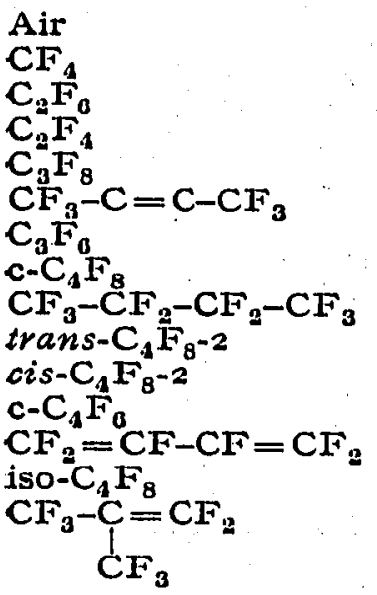 & $\begin{array}{l}0.70 \\
0.82 \\
1.44 \\
1.91 \\
3.53 \\
5.91 \\
6.61 \\
10.5 \\
10.6 \\
16.9 \\
\text { n.a. } \\
18.0 \\
22.3 \\
\text { n1.a. }\end{array}$ & $\begin{array}{l}0.49 \\
0.57 \\
1.00 \\
1.33 \\
2.45 \\
4.10 \\
4.59 \\
7.36 \\
7.36 \\
11.74 \\
11 . a . \\
12.50 \\
\text { r..49 } \\
\text { n.a. }\end{array}$ & $\begin{array}{l}0.65 \\
0.71 \\
0.96 \\
1.09 \\
1.55 \\
1.92 \\
2.10 \\
2.90 \\
2.90 \\
3.50 \\
\text { n.a. } \\
3.95 \\
4.55 \\
\text { n.a. }\end{array}$ & $\begin{array}{l}0.68 \\
0.74 \\
1.00 \\
1.14 \\
1.62 \\
2.00 \\
2.19 \\
3.02 \\
3.02 \\
3.65 \\
\text { n.a. } \\
4.12 \\
4.74 \\
\text { n.a. }\end{array}$ & $\begin{array}{l}0.66 \\
0.66 \\
0.81 \\
0.92 \\
1.19 \\
1.39 \\
1.47 \\
1.94 \\
1.94 \\
2.18 \\
\text { n.a. } \\
2.44 \\
2.73 \\
\text { n.a. }\end{array}$ & $\begin{array}{l}0.82 \\
0.82 \\
1.00 \\
1.14 \\
1.47 \\
1.72 \\
1.82 \\
2.39 \\
2.39 \\
2.69 \\
\text { n.a. } \\
3.01 \\
3.37 \\
\text { n.a. } \\
5.62\end{array}$ & $\begin{array}{c}\text { I.03 } \\
\text { I.I7 } \\
\text { I.62 } \\
1.89 \\
2.73 \\
3.51 \\
3.84 \\
5.40 \\
5.4 .0 \\
6.48 \\
7.30 \\
7.45 \\
8.60 \\
10.4\end{array}$ & $\begin{array}{l}0.64 \\
0.72 \\
1.00 \\
1.17 \\
1.67 \\
2.17 \\
2.37 \\
3.33 \\
3.33 \\
4.00 \\
4.51 \\
4.60 \\
5.31 \\
6.42\end{array}$ & $\begin{array}{l}1.03 \\
1.13 \\
1.47 \\
1.68 \\
2.21 \\
2.75 \\
2.96 \\
3.90 \\
3.90 \\
4.98 \\
\text { 1.a. } \\
5.02 \\
5.63 \\
\text { n.a. }\end{array}$ & $\begin{array}{l}0.70 \\
0.77 \\
1.00 \\
1.14 \\
1.50 \\
1.87 \\
2.01 \\
2.65 \\
2.65 \\
3.39 \\
11.9 . \\
3.42 \\
3.83 \\
1 . a . \\
6.29\end{array}$ \\
\hline
\end{tabular}

a $t_{m}=$ Retention time in minutes to peals.

b $R R V=$ Relative retention volume with respect to perfluoroethane.

TABLE II

RELATIVE RETENTION VOLUMES OF SEVERAI Fluorocarions ON PORAPAK TYPE $N$ $\mathrm{C}_{2} \mathrm{~F}_{0}=$ x.00. Helium carrier gas flow rate: $60 \mathrm{ml} / \mathrm{min}$; column material: $50 / 80$ mesh.

\begin{tabular}{|c|c|c|c|c|c|c|}
\hline \multirow[t]{2}{*}{ Compound } & \multicolumn{2}{|c|}{$5 \mathrm{ft}$. at $\mathrm{I00^{ \circ }}$} & \multicolumn{2}{|c|}{$5 \mathrm{ft}$. at $\mathrm{I}_{50^{\circ}}$} & \multicolumn{2}{|c|}{ ro ft. at $I 75^{\circ}$} \\
\hline & $t_{m} \mathbf{a}$ & $R R V^{\mathrm{b}}$ & $t_{m}$ & $R R V$ & $t_{m}$ & $R R V$ \\
\hline 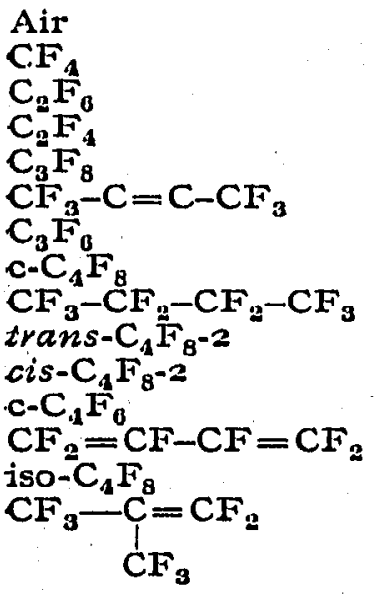 & $\begin{array}{c}0.60 \\
0.71 \\
1.22 \\
1.56 \\
2.87 \\
4.62 \\
4.99 \\
7.84 \\
8.44 \\
12.53 \\
\text { n.a. } \\
12.53 \\
16.2 \\
\text { 11.a. }\end{array}$ & $\begin{array}{r}0.49 \\
0.58 \\
1.00 \\
1.27 \\
2.35 \\
3.79 \\
4.09 \\
6.13 \\
6.92 \\
10.27 \\
1.2 . \\
10.27 \\
13.28 \\
\text { n.a. }\end{array}$ & $\begin{array}{l}0.58 \\
0.58 \\
0.76 \\
0.86 \\
1.19 \\
1.48 \\
1.57 \\
2.15 \\
2.24 \\
2.56 \\
11.2 . \\
2.83 \\
3.29 \\
\text { n.a. } \\
5.90\end{array}$ & $\begin{array}{l}0.76 \\
0.76 \\
1.00 \\
1.12 \\
1.57 \\
1.95 \\
2.07 \\
2.83 \\
2.93 \\
3.37 \\
\text { n.a. } \\
3.72 \\
4.33 \\
\text { n.a. } \\
7.76\end{array}$ & $\begin{array}{l}1.17 \\
1.17 \\
1.44 \\
1.62 \\
2.03 \\
2.35 \\
2.95 \\
3.13 \\
3.13 \\
3.46 \\
3.70 \\
3.90 \\
4.35 \\
4.65 \\
7.32\end{array}$ & $\begin{array}{l}0.8 \mathrm{I} \\
0.8 \mathrm{I} \\
1.00 \\
1.12 \\
1.4 \mathrm{I} \\
1.63 \\
2.05 \\
2.17 \\
2.17 \\
2.40 \\
2.57 \\
2.7 \mathrm{I} \\
3.02 \\
3.23 \\
5.08\end{array}$ \\
\hline
\end{tabular}

a $t_{n}=$ Retention time in minutes to peak.

- RRV = Relative retention volume with respect to perfluoroethane: 
TABLE III

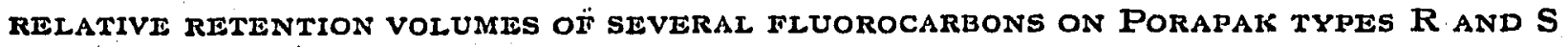
$\mathrm{C}_{2} \mathrm{~F}_{0}=$ r.00. Helium carrier gas flow rate: $60 \mathrm{ml} / \mathrm{min}$; column material : $50 / 80 \mathrm{mesh}$.

\begin{tabular}{|c|c|c|c|c|c|c|c|c|}
\hline \multirow[t]{2}{*}{ Compound } & \multicolumn{2}{|c|}{$\begin{array}{l}\text { Type R } \\
6 \text { ft. at } \text { xoo }\end{array}$} & \multicolumn{2}{|c|}{$\begin{array}{l}\text { Type R } \\
6 \text { ft. at } I 50^{\circ} \\
\end{array}$} & \multicolumn{2}{|c|}{$\begin{array}{l}\text { Types } \\
6 \text { ft. at } 100^{\circ}\end{array}$} & \multicolumn{2}{|c|}{$\begin{array}{l}\text { Type S } \\
6 \text { ft. at } 550^{\circ}\end{array}$} \\
\hline & $t_{m}{ }^{a}$ & $R R V^{\mathbf{b}}$ & $t_{m}$ & $R R V$ & $t_{m}$ & $R R V$ & $t_{m}$ & $R R V$ \\
\hline 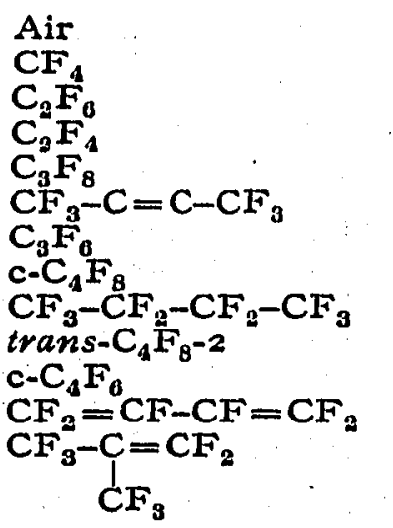 & $\begin{array}{r}0.85 \\
0.95 \\
1.48 \\
1.86 \\
3.00 \\
4.30 \\
4.33 \\
6.88 \\
7.56 \\
8.80 \\
9.62 \\
\times 2.30 \\
-\end{array}$ & $\begin{array}{l}0.57 \\
0.64 \\
1.00 \\
1.26 \\
2.03 \\
2.91 \\
2.93 \\
4.65 \\
5.11 \\
5.95 \\
6.50 \\
8.31 \\
-\end{array}$ & $\begin{array}{l}0.86 \\
0.86 \\
1.07 \\
1.17 \\
1.54 \\
1.81 \\
1.80 \\
2.39 \\
2.57 \\
2.57 \\
2.87 \\
3.31 \\
6.10\end{array}$ & $\begin{array}{l}0.80 \\
0.80 \\
1.00 \\
1.10 \\
1.44 \\
1.69 \\
1.68 \\
2.23 \\
2.40 \\
2.40 \\
2.68 \\
3.09\end{array}$ & $\begin{array}{r}0.80 \\
0.90 \\
1.41 \\
1.71 \\
2.98 \\
2.98 \\
4.19 \\
6.90 \\
7.63 \\
8.80 \\
9.98 \\
12.5\end{array}$ & $\begin{array}{l}0.57 \\
0.64 \\
1.00 \\
1.21 \\
2.11 \\
2.11 \\
2.97 \\
4.89 \\
5.41 \\
6.24 \\
7.08 \\
8.86\end{array}$ & $\begin{array}{l}0.75 \\
0.80 \\
1.00 \\
1.10 \\
1.42 \\
1.42 \\
1.70 \\
2.30 \\
2.45 \\
2.45 \\
2.70 \\
3.20 \\
5.69\end{array}$ & $\begin{array}{l}0.75 \\
0.80 \\
1.00 \\
1.12 \\
1.42 \\
1.42 \\
1.70 \\
2.30 \\
2.45 \\
2.45 \\
2.70 \\
3.20 \\
\\
5.69\end{array}$ \\
\hline
\end{tabular}

a $t_{m}=$ Retention time in minutes to peak.

- $R R V=$ Relative retention volume with respect to perfluoroethane.

\section{TABLE IV}

RElative retention volumes of several fluorocarbons on Porapais type $Q$ $\mathrm{C}_{\mathrm{g}} \mathrm{F}_{\mathrm{g}}=\mathrm{I} .00$. Helium carrier gas flow rate: $60 \mathrm{ml} / \mathrm{min}$; column material: $50 / 80 \mathrm{mesh}$.

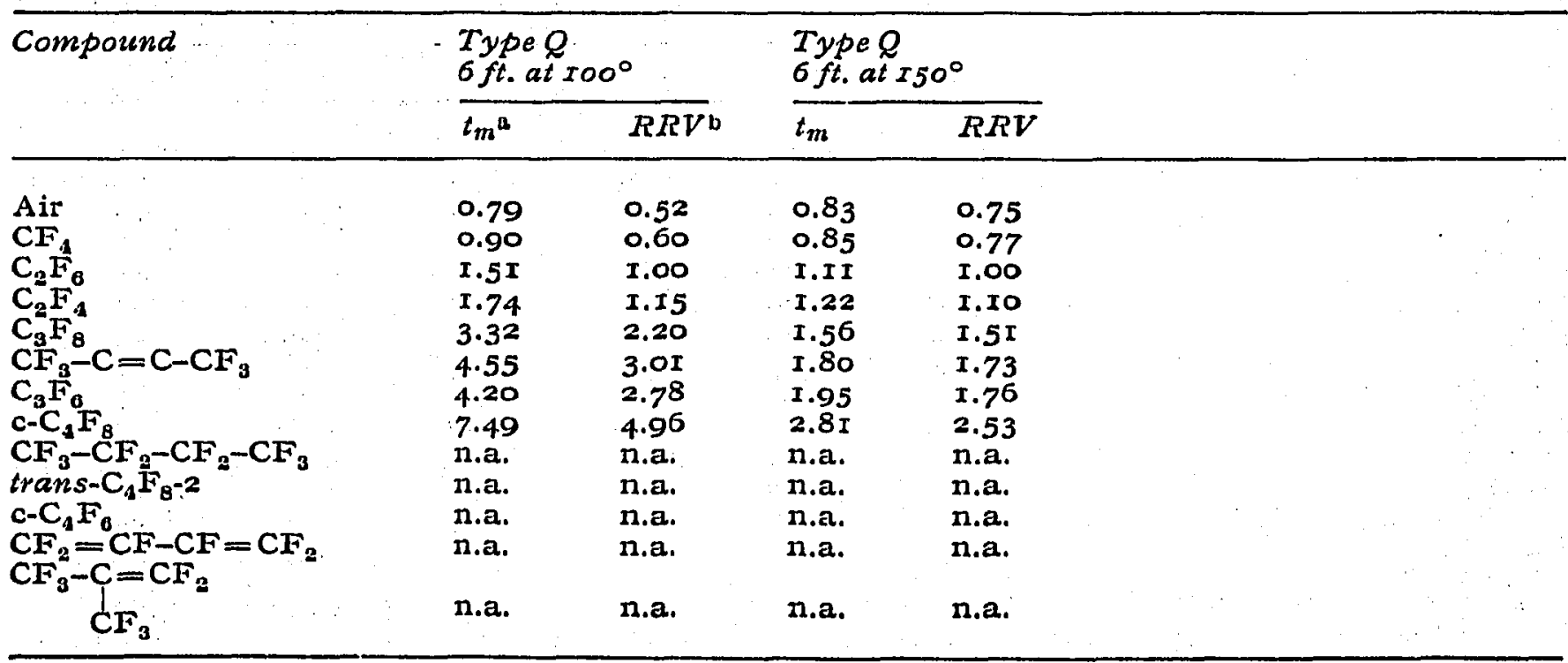

a $t_{m}=$ Retention time in minutes to peak.

- RRV = Relative retention volume with respect to perfluoroethane. 
greater than $25 \mathrm{~min}$, and a notation of n.a. implies that a compound was not tested. Poropalk Type $\mathbf{P}$ does not effectively separate the compounds of interest and hence results for this column are not listed. A ten foot column of Poropak.Type T maintained at $I 50^{\circ}$ was found to be the most effective for the separation of a mixture containing air and a large number of low molecular weight fluorocarbons. A GSC chromatogram of a complex, gaseous fluorocarbon mixture obtained with the aid of a ten foot; Poropak Type $T$ column is shown in Fig. 1 . The column temperature was maintained at $I 50^{\circ}$ and the separation was completed in approximately $I 7 \mathrm{~min}$. The perfluorocyclobutane and perfluorobutane were not resolved on this column.

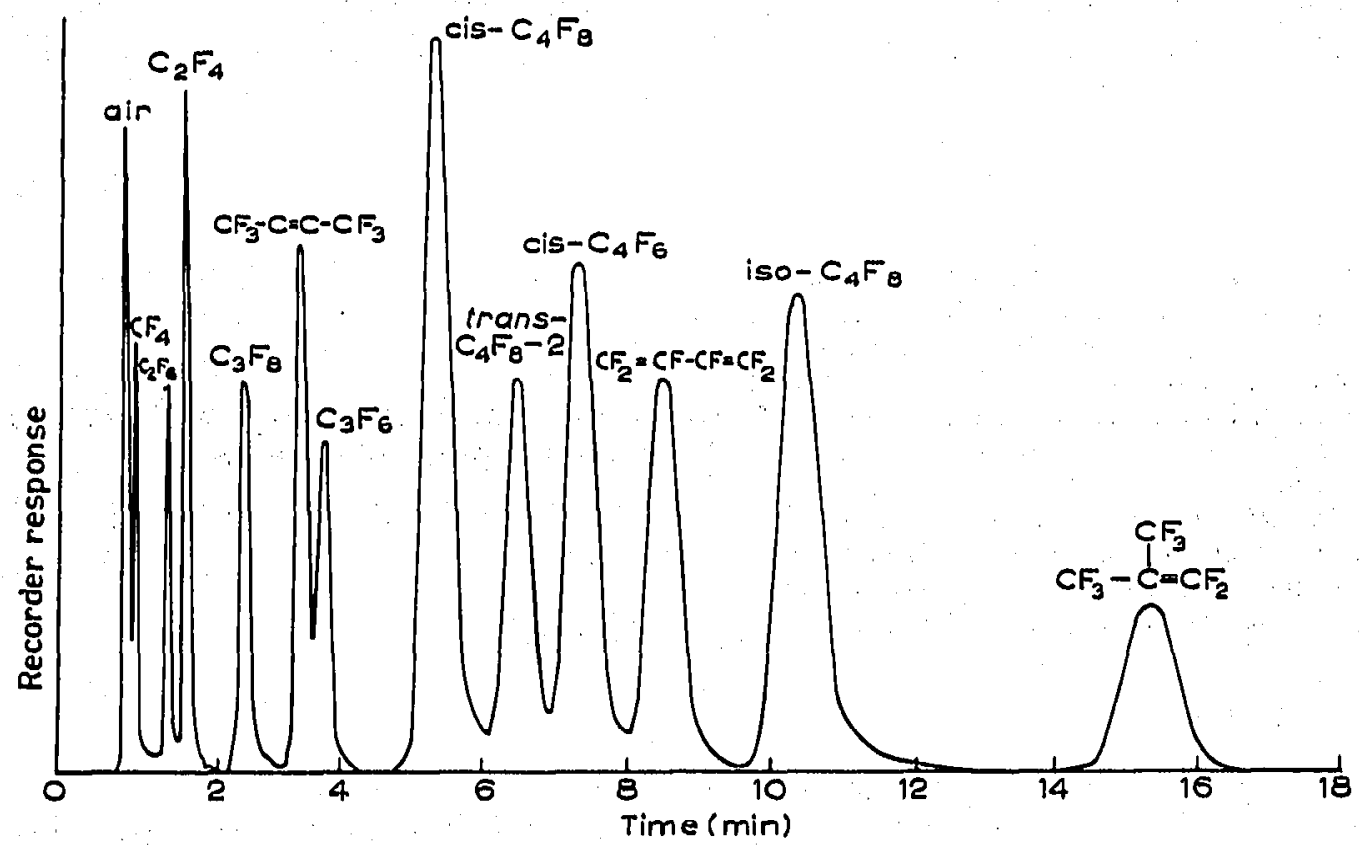

Fig. x. Gas-solid chromatogram of fluorocarbons.

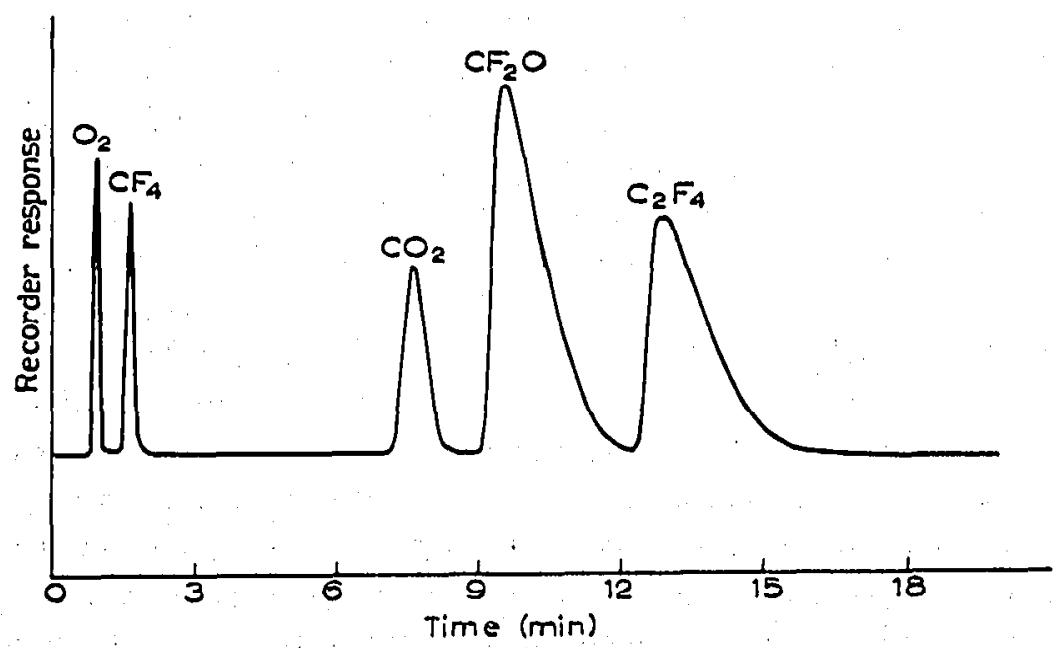

Fig. 2. Typical chromatogram of $\mathrm{C}_{2} \mathrm{~F}_{4}$ oxidation products. 


\section{Fluorocarbon combustion products}

The major equilibrium products associated with fluorocarbon combustion include $\mathrm{O}_{2}, \mathrm{CF}_{4}, \mathrm{CO}_{2}, \mathrm{CF}_{2} \mathrm{O}$ and $\mathrm{C}_{2} \mathrm{~F}_{4}$. A GSC chromatogram of these compounds obtained with the aid of a six foot composite column consisting of two feet of $50 / 80$ mesh Poropak type $T$ followed by four feet of $50 / 80$ mesh Poropak $N$ is shown in Fig. 2. The column temperature was maintained at $23^{\circ}$ and the helium carrier gas flow rate was $60 \mathrm{ml} / \mathrm{mnin}$.

\section{ACIKNOWLEDGEMENT}

This research was sponsored by the Air Force Office of Scientific Research, Office of Aerospace Research, United States Air Force, under Grant Number AFAFOSR-II44-67.

\section{REFERENCES}

$x$ D. Evans and J. Tatiow, $J$. Chem. Soc, (I955)"II84.

2 J. Godseli, M. Stacey and J. Tatlow, Naluve, i78 (I956) 199.

3 R. Stephens and J. TAtrow, Chem. Ind. (London), (r957) 821.

4 R. Smith and J. Tatlow, J. Chem. Soc., (I957) 2505.

5 D. Evans and J. Tatlow, in D. H. Diesty (Editor), Vapour Phase Chromatography, Proceedings of the First Symposium, London, June, r956, Academic Press, New York, 1957, p. 256.

6 T. M. ReED, Anal. Chem., 30 (1958) $22 \mathrm{I}$.

7 J. Sperpinter, Chim. Anal. (Faris), $4 \mathrm{I}$ (1959) I 46.

8 R. Campbeli and B. Gudzinowicz, Anal. Chem., 33 (I96I) 842.

9 S. GReEn ANd F. WaChi, Anal. Chem., 35 (I963) 928.

Io G. A. DRenNan and R. A. Matula, J. Chromatog., 34 (т968) 77 .

J. Chromalog., 35 (1968) 21 7-222 